\title{
Metadados para descrição de datasets e recursos informacionais do "Portal Brasileiro de Dados Abertos"
}

Fábio Mosso Moreira

Doutorando pelo Programa de Pós Graduação em Ciência da Informação da Universidade Estadual Paulista, Campus de Marília.

Ricardo César Gonçalves Sant'Ana

Docente da Universidade Estadual Paulista, Campus de Tupã. Docente do Programa de PósGraduação em Ciência da Informação da Universidade Estadual Paulista, Campus de Marília. Doutorado em Ciência da Informação pela Universidade Estadual Paulista, Campus de Marília. Livre-docente em Sistemas de Informações Gerenciais pela Universidade Estadual Paulista, Campus de Tupã.

Plácida Leopoldina Ventura Amorim da Costa Santos

Docente no Programa de Pós-Graduação em Ciência da Informação da Universidade Estadual Paulista, Campus de Marília. Doutorado em Semiótica e Lingüística Geral pela FFLCH/USP. Livre-docente em Catalogação pela Universidade Estadual Paulista, Campus de Marília.

Zaira Regina Zafalon

Docente na Universidade Federal de São Carlos (UFSCar). Doutora em Ciência da Informação pela Universidade Estadual Paulista, Campus de Marília.

http://dx.doi.org/10.1590/1981-5344/2947

O Governo brasileiro e os fundadores da Open Government Partnership adotaram, em 2011, a declaração de Governo Aberto, anunciando planos de ação para tornar conjuntos de dados acessíveis baseado nos princípios de Dados Governamentais Abertos, o que resultou na implantação do Portal Brasileiro de Dados Abertos. Por meio de um sistema de recuperação é possível realizar buscas neste website, identificando fontes de dados sobre saúde, transporte, segurança pública, educação, gastos governamentais e processo 
eleitoral. Considerando que o compartilhamento de dados pode se tornar uma atividade complexa devido à baixa carga semântica deste tipo de informação, durante a busca por datasets governamentais na Web podem ser encontrados problemas como acesso parcial, superficial e de difícil compreensão dos dados. A descrição eficiente dos recursos informacionais e a representação adequada dos conjuntos de dados podem amenizar estes fatores, e contribuir com a obtenção de resultados relevantes no processo de recuperação. Levanta-se a questão sobre quais elementos de metadados os serviços de disponibilização de dados governamentais estão utilizando para representar seus recursos informacionais. Para tanto, esta pesquisa tem como objetivo estudar $o$ processo de recuperação de dados no Portal Brasileiro de Dados Abertos analisando os elementos de metadados utilizados na representação dos datasets.

Palavras-chave: Metadados; Recuperação; Dados Governamentais; Dataset; Recursos Informacionais.

\section{Metadata for description of datasets and information resources of "Portal Brasileiro de Dados Abertos"}

The Brazilian government and the founders of the Open Government Partnership adopted in 2011 the Declaration of Open Government, announcing action plans to make datasets accessible according with the eight principles of Open Government Data, which resulted in the implementation of the "Portal Brasileiro de Dados Abertos". Through an information retrieval system, the users can search datasets about health, transportation, public safety, education, government spending and electoral process. Share government data in Web can become a complex activity and the low semantic level of this type of information can causes problems during the search like superficial access and dificult undertanding of datasets. An Efficient description of information resources and an appropriate representation of the datasets can mitigate these problems and contribute to achieving relevant results in the retrieval process. This research brings the question about which elements of metadata are using by government services to represent its information 
resources. In this sense, the aim of this research is study the process of data sharing in the "Portal Brasileiro de Dados Abertos" and identifying the metadata used for the representation of datasets.

Keywords: Metadata; Retrieval; Government Data; Dataset; Information Resources.

Recebido em 01.10.2016 Aceito em 07.06.2017

\section{Introdução}

A Internet é uma tecnologia que pode viabilizar maior interação entre a administração pública e a sociedade, tanto para os cidadãos que buscam por informações para participação do desenvolvimento das políticas públicas quanto para o Governo no fornecimento de serviços informacionais mais eficientes.

Sant'Ana (2009) ressalta a importância dos governos utilizarem-se de recursos tecnológicos para a disponibilização de informações sobre suas ações, fornecendo dados sobre: planos e programas governamentais; orçamentos, arrecadação e fontes de receita; licitações, contratos e seus aditivos; e dados sobre funcionários municipais e município. $O$ acesso a este conteúdo pode permitir maior acompanhamento das ações do poder público por parte da sociedade, gerando maior confiança no processo político.

A responsabilidade das administrações públicas em disponibilizar informações sobre suas ações foi intensificada com a promulgação da Lei Federal no 12.527/2011. A Lei de Acesso à Informação (LAI) adicionou novas obrigações às instituições públicas, reforçando o dever do Estado de garantir o Direito de acesso à informação de forma transparente, clara e em linguagem de fácil compreensão, dispondo também sobre a obrigação da divulgação de informações em sítios oficiais da rede mundial de computadores - Internet (BRASIL, 2011).

No Brasil, uma das primeiras iniciativas no sentido de se utilizar a Internet como meio para disponibilização de dados governamentais ocorreu em 1994, com o Portal da Transparência da Controladoria-Geral da União (BRASIL, 2017a), que trazia informações sobre a distribuição de recursos financeiros do Governo Federal, como transferências e aplicações diretas (PLATT NETO; CRUZ; VIEIRA, 2006). Com esta ação, o país começou a incorporar os preceitos de Governo Eletrônico, adotando a Internet como tecnologia chave para divulgação de informações governamentais e promoção do acompanhamento público de modo proativo.

O Governo Eletrônico envolve tanto questões tecnológicas quanto organizacionais, mesclando fatores relacionados com a utilização de recursos de informática e o tratamento da efetividade operacional da 
gestão pública. Os objetivos perseguidos são: transparência, acessibilidade, prestação de contas, serviços públicos eficientes, políticas públicas e envolvimento dos usuários. Ao incorporá-los, os órgãos governamentais buscam eficiência, eficácia e melhoria na qualidade das informações disponibilizadas (ANDERSEN; HENRIKISEN, 2006).

Concomitante à evolução do Governo Eletrônico no país, o governo brasileiro, no ano de 2011, e os governos de Estados Unidos, Reino Unido, Tailândia, Filipinas, Noruega, África do Sul e México, fundaram uma iniciativa internacional para difundir e incentivar globalmente práticas relacionadas à transparência governamental, acesso à informação pública e participação social. Os fundadores da Open Government Partnership (OPG) adotaram a declaração de Governo Aberto, anunciando planos de ação para tornar conjuntos de dados acessíveis atendendo aos princípios de dados abertos (CONTROLADORIA GERAL DA UNIÃO, 2016).

Como resultado do compromisso firmado no âmbito do OPG, no primeiro Plano de Ação do Governo Aberto, o Brasil implantou o Portal Brasileiro de Dados Abertos (BRASIL, 2017b), disponibilizado para que pessoas possam encontrar dados e informações públicas. O Portal atua como um grande catálogo digital que facilita a busca e uso de dados publicados pelos órgãos governamentais, buscando proporcionar ao cidadão um melhor entendimento sobre o processo governamental, o acesso aos serviços públicos, o controle das contas públicas e a participação do cidadão no planejamento das políticas públicas (BRASIL, 2016).

Por meio de um sistema de recuperação é possível realizar buscas no Portal Brasileiro de Dados Abertos, identificando fontes de dados sobre saúde suplementar, sistemas de transporte, segurança pública, educação, gastos governamentais e processo eleitoral.

Considerando que o compartilhamento de dados pode se tornar uma atividade complexa devido à baixa carga semântica deste tipo de informação ${ }^{1}$, durante a busca por conjuntos de dados governamentais podem ser encontrados problemas relacionados com o acesso parcial, superficial e de difícil compreensão das bases, o que acaba inviabilizando possíveis análises e interpretações.

A descrição eficiente dos recursos informacionais e a representação adequada dos conjuntos de dados podem amenizar estes fatores, contribuindo com a obtenção de resultados relevantes no processo de recuperação. Para Moura e Fernandes (2001), a representação de um recurso informacional busca a padronização e normalização no tratamento e recuperação da informação, e tem como objetivo fornecer um conjunto de elementos para a descrição de recursos informacionais; obter resultados mais precisos no processo de busca; e estabelecer padrões de metadados, modelos e protocolos, e sua integração com os mecanismos de busca.

Elemento básico, formado por signo ou conjunto finito de signos que não contém, intrinsicamente, um componente semântico, mas somente elementos sintáticos (SANTOS; SANT'ANA, 2002). 
$\mathrm{Na}$ administração pública é fundamental que os documentos eletrônicos, principalmente aqueles que contém conjunto de dados disponibilizados pelos órgãos governamentais, sejam estruturados e organizados de tal forma que facilite sua recuperação, introduzindo níveis de normalização no desenvolvimento, processamento, armazenamento, recuperação e conservação, de forma que assegure a interoperabilidade da informação no ciclo completo de compartilhamento (MARTINES USERO, 2007).

Neste contexto, levanta-se a questão sobre quais elementos de metadados os serviços de disponibilização de dados governamentais estão utilizando para representar seus recursos informacionais. Para tanto, esta pesquisa tem como objetivo estudar o processo de recuperação de dados no Portal Brasileiro de Dados Abertos, de modo a analisar os elementos de metadados utilizados na representação dos datasets.

Para estruturar esta questão e atender aos objetivos propostos, a Ciência da Informação tem um importante papel na medida em que se torna fundamental proporcionar a representação adequada do conteúdo informacional para garantir resultados relevantes no processo de recuperação dos conjuntos de dados. Segundo Hawkins (2001), a Ciência da Informação estuda os processos de geração, organização, representação, processamento, distribuição, comunicação e uso da informação, no contexto da busca por informações para atender necessidades informacionais.

Adotou-se, como procedimento metodológico, a pesquisa qualitativa de caráter exploratório, realizada a partir de uma coleta realizada no Portal Brasileiro de Dados Abertos. Antecedente à coleta, realizou-se uma pesquisa teórica, para contextualizar o tema envolvendo a utilização de tecnologias no compartilhamento de dados governamentais, e aspectos relacionados à representação de recursos informacionais na Web.

A partir de uma coleta de dados realizada no Portal Brasileiro de Dados Abertos, foi possível traçar um cenário da disponibilização de dados governamentais na Web, estudando o processo de recuperação dos recursos informacionais e a maneira como são apresentados os elementos de metadados que os representam. Segundo Sant'Ana (2013), o processo de recuperação de dados pode ser entendido como a fase do Ciclo de Vida dos Dados em que ocorre ações relacionadas à disponibilização dos dados para consulta e visualização

No total foram analisados vinte e cinco datasets (Quadro 1), localizados por meio da realização de pesquisas utilizando o sistema de busca interno do Portal Brasileiro de Dados Abertos. Para a realização das pesquisas, foram utilizados cinco termos de busca (Agricultura, Saúde, Infraestrutura, Educação e Segurança), definidos de modo que, no escopo final, constassem recursos informacionais abrangendo segmentos distintos trabalhados pelo Governo. Após a realização da pesquisa utilizando cada um dos termos de busca, foram selecionados os cinco primeiros resultados listados pelo sistema de recuperação para que fosse analisada 
a apresentação dos elementos de metadados utilizados na descrição do dataset.

Quadro 1 - Escopo de datasets localizados no Portal Brasileiro de Dados Abertos

\begin{tabular}{|c|c|c|}
\hline Segmento & $\begin{array}{l}\text { Título dos } \\
\text { datasets }\end{array}$ & Hiperlink \\
\hline \multirow{5}{*}{ Agricultura } & $\begin{array}{l}\text { Aprovação } \\
\text { Sistema BNDES } \\
\text { Setor CNAE } \\
\text { Agricultura e } \\
\text { Pesca } 2015\end{array}$ & http://dados.gov.br/dataset/bndes ap 2015 \\
\hline & $\begin{array}{l}\text { Indicadores sobre } \\
\text { Brasil Sem } \\
\text { Miséria }\end{array}$ & http://dados.gov.br/dataset/brasil-sem-miseria \\
\hline & $\begin{array}{l}\text { Indicadores sobre } \\
\text { Infraestrutura } \\
\text { Hídrica - } \\
\text { Agricultura } \\
\text { Irrigada } \\
\end{array}$ & $\begin{array}{l}\text { http://dados.gov.br/dataset/infraestrutura-hidrica-agricultura- } \\
\text { irrigada }\end{array}$ \\
\hline & $\begin{array}{l}\text { Indicadores sobre } \\
\text { PRONAF - } \\
\text { Programa } \\
\text { Nacional de } \\
\text { Fortalecimento da } \\
\text { Agricultura } \\
\text { Familiar } \\
\end{array}$ & $\begin{array}{l}\text { http://dados.gov.br/dataset/pronaf-programa-nacional-de- } \\
\text { fortalecimento-da-agricultura-familiar }\end{array}$ \\
\hline & $\begin{array}{l}\text { Indicadores sobre } \\
\text { Seguro da } \\
\text { Agricultura } \\
\text { Familiar - SEAF }\end{array}$ & http://dados.gov.br/dataset/seguro-da-agricultura-familiar-seaf \\
\hline \multirow{5}{*}{ Educação } & $\begin{array}{l}\text { Indicadores sobre } \\
\text { Educação no } \\
\text { Campo }\end{array}$ & http://dados.gov.br/dataset/educacao-no-campo \\
\hline & $\begin{array}{l}\text { Indicadores sobre } \\
\text { Ensino Básico - } \\
\text { Mais Educação }\end{array}$ & http://dados.gov.br/dataset/ensino-basico-mais-educacao \\
\hline & $\begin{array}{l}\text { Microdados do } \\
\text { Censo da } \\
\text { Educação } \\
\text { Superior }\end{array}$ & $\begin{array}{l}\text { http://dados.gov.br/dataset/microdados-do-censo-da-educacao- } \\
\underline{\text { superior }}\end{array}$ \\
\hline & $\begin{array}{l}\text { Microdados do } \\
\text { Exame Nacional } \\
\text { de Desempenho } \\
\text { de Estudantes - } \\
\text { Enade }\end{array}$ & $\begin{array}{l}\text { http://dados.gov.br/dataset/microdados-do-exame-nacional-de- } \\
\underline{\text { desempenho-de-estudantes-enade }}\end{array}$ \\
\hline & $\begin{array}{l}\text { Taxa de } \\
\text { analfabetismo } \\
\text { funcional do Brasil } \\
\text { de } 2001 \text { a } 2009\end{array}$ & $\frac{\text { http://dados.gov.br/dataset/taxa-de-analfabetismo-funcional- }}{\underline{2001-2009}}$ \\
\hline \multirow[b]{2}{*}{ Infraestrutura } & $\begin{array}{l}\text { Indicadores sobre } \\
\text { PAC } \\
\text { Equipamentos }\end{array}$ & http://dados.gov.br/dataset/pac-equipamentos \\
\hline & $\begin{array}{l}\text { Infraestrutura } \\
\text { Turística - 1ํㅗ․ } \\
\text { Balanço do PAC } \\
2015\end{array}$ & http://dados.gov.br/dataset/infraturistica \\
\hline
\end{tabular}




\begin{tabular}{|c|c|c|}
\hline Segmento & $\begin{array}{c}\text { Título dos } \\
\text { datasets }\end{array}$ & Hiperlink \\
\hline & $\begin{array}{l}\text { Manifestações de } \\
\text { Usuários } \\
\text { Registrados na } \\
\text { Agência Nacional } \\
\text { de Aviação Civil - } \\
\text { ANAC } \\
\end{array}$ & $\begin{array}{l}\text { http://dados.gov.br/dataset/manifestacoes-de-usuarios- } \\
\text { registrados-na-anac }\end{array}$ \\
\hline & $\begin{array}{l}\text { Movimento dos } \\
\text { Aeroportos } \\
\text { Administrados } \\
\text { pela Infraero }\end{array}$ & $\begin{array}{l}\text { http://dados.gov.br/dataset/movimento-dos-aeroportos- } \\
\text { administrados-pela-infraero }\end{array}$ \\
\hline & $\begin{array}{l}\text { Projetos da } \\
\text { Carteira } \\
\text { COSIPLAN }\end{array}$ & http://dados.gov.br/dataset/mpog cosiplan2 \\
\hline \multirow{5}{*}{ Saúde } & $\begin{array}{l}\text { Distribuição de } \\
\text { Agentes } \\
\text { Comunitários de } \\
\text { Saúde - ACS }\end{array}$ & http://dados.gov.br/dataset/acs1 \\
\hline & $\begin{array}{l}\text { Indicadores sobre } \\
\text { Saúde } \\
\text { Complementar }\end{array}$ & http://dados.gov.br/dataset/saude-complementar \\
\hline & $\begin{array}{l}\text { Indicadores sobre } \\
\text { Saúde da Família }\end{array}$ & http://dados.gov.br/dataset/saude-da-familia \\
\hline & $\begin{array}{l}\text { Limites das } \\
\text { regiões de saúde }\end{array}$ & http://dados.gov.br/dataset/limites regiao saude \\
\hline & $\begin{array}{l}\text { Unidades Básicas } \\
\text { de Saúde - UBS }\end{array}$ & http://dados.gov.br/dataset/unidades-basicas-de-saude-ubs \\
\hline \multirow{5}{*}{ Segurança } & $\begin{array}{l}\text { Indicadores sobre } \\
\text { Aprimoramento } \\
\text { das Atividades de } \\
\text { Segurança } \\
\text { Pública }\end{array}$ & $\begin{array}{l}\text { http://dados.gov.br/dataset/aprimoramento-das-atividades-de- } \\
\text { seguranca-publica }\end{array}$ \\
\hline & $\begin{array}{l}\text { Indicadores sobre } \\
\text { Força Nacional de } \\
\text { Segurança } \\
\text { Pública }\end{array}$ & $\begin{array}{l}\text { http://dados.gov.br/dataset/forca-nacional-de-seguranca- } \\
\text { publica }\end{array}$ \\
\hline & $\begin{array}{l}\text { Indicadores sobre } \\
\text { Segurança } \\
\text { Pública }\end{array}$ & http://dados.gov.br/dataset/seguranca-publica \\
\hline & $\begin{array}{l}\text { Postos e } \\
\text { delegacias do } \\
\text { Departamento de } \\
\text { Polícia Federal }\end{array}$ & http://dados.gov.br/dataset/postos-e-delegacias-do-dpf \\
\hline & $\begin{array}{l}\text { Segurança } \\
\text { Pública com } \\
\text { Cidadania }\end{array}$ & http://dados.gov.br/dataset/mpog seguranca publica \\
\hline
\end{tabular}

Fonte: Os autores.

A análise dos datasets identificados foi realizada por meio do método de observação direta, direcionada na identificação dos principais elementos de metadados descritivos que eram apresentados durante 0 processo de recuperação. A identificação dos elementos de metadados foi embasada pelo Padrão de Metadados do Governo Eletrônico (e-PMG 1.1), na qual foram verificadas a definição dos metadados deste padrão, servindo para direcionar a analise realizada no Portal. 
Os dados obtidos foram sistematizados por meio de tabelas (Tabela 1 e Tabela 2), na qual os rótulos de linha referem-se aos elementos de metadados identificados, e os rótulos de coluna referem-se aos datasets analisados. A tabela foi completa conforme os elementos eram identificados no conteúdo do dataset, verificando-se a frequência com que determinado elemento de metadado era apresentado no escopo total dos datasets analisados, e quais dos elementos identificados podiam estar associados aos elementos do e-PMG 1.1 .

Para relacionar os elementos de metadados utilizados na representação dos datasets verificados com os elementos de metadados do e-PMG 1.1, aplicou-se o método Crosswalk. Segundo Baca (2008), o Crosswalk é um produto visual e textual do processo de mapeamento de elementos que mostra o relacionamento e equivalência entre dois ou mais formatos de metadados. São utilizados para comparar elementos de metadados entre padrões distintos, e avaliar o grau de interoperabilidade e possibilidades de conversão da estrutura de dados dos recursos informacionais de um formato para outro, mostrando as relações de similaridade e diferença entre os padrões. O Crosswalk também permite ao sistema de busca pesquisar campos com o mesmo conteúdo ou similar em diferentes fontes de dados dando suporte à interoperabilidade semântica.

O artigo está estruturado em quatro seções: esta introdução, contendo uma contextualização geral do objeto de estudo e objetivos da pesquisa, acompanhada da descrição metodológica e de coleta de dados; uma segunda seção contendo conceitos levantados durante a pesquisa teórica e uma subseção descrevendo o e-PMG 1.1; uma terceira seção contendo os resultados obtidos a partir da análise dos dados coletados; e a quarta, e última seção, contendo as considerações finais identificadas durante a realização da pesquisa.

\section{Metadados para recuperação de recursos informacionais na Web}

A Web pode ser considerada a maior coleção de documentos eletrônicos mundiais, com conteúdo alimentado dinamicamente por bases de dados e inputs dos usuários. Entretanto, a maior parte da informação disponível possui qualidade variável, e o desafio consiste em encontrar informações relevantes neste universo.

Para facilitar a localização de informações relevantes na Web, Baca (2008) ressalta que é necessária a descrição eficiente dos recursos para dar sentido à vasta quantidade de informação disponível, o que implica a representação e a apresentação adequada dos documentos.

A expansão das unidades de informação e o crescimento exponencial de acervos documentais em ambientes digitais trouxeram a necessidade de reaver processos para satisfazer a demanda informacional de diferentes públicos. Segundo Zafalon (2012), a produção e a proliferação de informação em ambientes digitais exigem a adoção de 
padrões para a representação dos documentos eletrônicos de modo que a recuperação e o acesso estejam garantidos pela identificação unívoca do recurso.

Representar recursos informacionais é atividade fundamental para o estabelecimento do processo comunicativo entre unidades de informação e usuários, principalmente em uma plataforma digital como a Web. Esta representação envolve a comunicação, aos usuários, dos documentos disponíveis de modo individualizado, reunidos com base em suas características de conteúdo ou de suas expressões e obras (ZAFALON, 2012).

Um documento tem a função de materializar uma informação, mas não necessariamente vincular a mesma à um suporte físico. Os documentos armazenados em um dispositivo eletrônico, apesar de não serem físicos, são entidades identificadas e estruturadas, contendo textos, gráficos, sons, imagens ou qualquer outra classe de informação que possa ser armazenada, editada, extraída e compartilhada entre sistemas de tratamento de informação (MARTINES USERO, 2007).

No processo de representação, aspectos como a integridade, a clareza, a precisão, a lógica e a consistência dos conteúdos dos documentos a serem representados devem ser resguardados, tendo em vista sempre o usuário e as necessidades por ele demonstrada (MEY, 1995).

Para Garrido Arilla ( $1999^{2}$ apud ZAFALON, 2012), é importante que seja feita uma representação codificada e econômica de um documento: representação pois reproduz certas características do documento; codificada porque identifica o documento a que se propôs identificar; e econômica porque busca proporcionar informação de um documento em um mínimo espaço e com o mínimo de símbolos possíveis.

Segundo Santos e Correa (2009), para representar existe a necessidade de se estabelecerem esquemas e regras de descrição padronizadas, no que se refere à forma e ao conteúdo das manifestações informacionais.

Para Foulonneuau e Riley (2008) alguns fatores são decisivos na escolha dos padrões para representação de recursos informacionais: a instituição (cultura organizacional, rotinas institucionais); o padrão dos elementos representativos; os documentos a serem representados; e os objetivos do projeto (para atender às necessidades identificadas).

Representar recursos informacionais de forma padronizada só é possível adotando convenções sintáticas e semânticas aplicadas por meio de padrões de estrutura de metadados descritivos e padrões de conteúdo (FERNANDES, 2005). A sintaxe fica por meio da ordem dos elementos dispostos para a representação, e a semântica baseia-se no significado estabelecido entre os elementos representados e 0 documento representado (ZAFALON, 2012).

2 GARRIDO ARILLA, M. R. Procedimientos automáticos de creación y transformación de los registros bibliográficos. Anales de Documentación, n. 4, p. 127-137, 2001. 
Baca (2008) ressalta que os padrões de metadados servem para modelar os atributos mais importantes do objeto que descreve, onde cada componente do padrão é delimitado por etiquetas que identificam o significado de cada pedaço de informação presente no objeto. Com base neste papel executado pelos metadados, para esta pesquisa define-se metadados como sendo o conjunto de atributos que apresentam o conteúdo informacional de um recurso que pode estar em meio eletrônico ou não (ALVES, 2005).

No meio eletrônico, Martines Usero (2007) destaca que os metadados podem auxiliar na representação de recursos informacionais por meio da convergência de formatos de codificação, da organização de conhecimento segundo estruturas que permitem o usuário atingir seus objetivos, e melhora na recuperação da informação, rotulando conteúdos para facilitar sua localização por meio de sistemas de busca.

Segundo Baca (2008), existem alguns padrões de metadados específicos para descrever recursos informacionais em um meio eletrônico, sendo os principais: Dublin Core $^{3}$ (conjunto de 15 elementos de informação que podem ser utilizados para descrever genericamente uma variedade de recursos) e o $\mathrm{RDF}^{4}$ (desenvolvido pelo W3C para codificar a descrição de recursos de modo que computadores possam 'entender', compartilhar e processar informação de modo útil e acrescentar semântica nos metadados).

A utilização de padrões de metadados pode ajudar os sistemas de busca na Web a responder consultas que exigem a extração e combinação de dados de múltiplas fontes, permitindo o acesso integrado a estes serviços. Serviços integrados de busca de dados têm o objetivo de fornecer ao usuário acesso uniforme às diversas fontes, as quais podem ser autônomas, heterogêneas e distribuídas. O objetivo principal é evitar que o usuário tenha que localizar as fontes de dados, interagir com cada uma isoladamente e combinar manualmente os dados provenientes de múltiplas fontes (LEVY, 2000).

O objeto de estudo analisado por esta pesquisa pode ser considerado um serviço de recuperação de conteúdo na Web que fornece acesso uniforme às fontes de dados provindas de distintos órgãos governamentais. Portanto, é valido considerar a utilização de um padrão específico de metadados para representação de recursos informacionais aplicados na esfera pública. Descreve-se então, o Padrão Metadados do Governo Eletrônico (e-PMG 1.1), cujos elementos e diretrizes de aplicação auxiliaram na identificação dos elementos utilizados para representação das bases de dados disponibilizadas no Portal Brasileiro de Dados Abertos, verificando os metadados apresentados durante 0 processo de recuperação.

De acordo com o Comitê Executivo do Governo Eletrônico (CEGE, 2014), o e-PMG é resultado da política de Infraestrutura Nacional de

\footnotetext{
${ }^{3}$ Mais informações sobre o Dublin Core podem ser obtidas em: <http://dublincore.org >. Acesso em: 12 set. 2017

${ }^{4}$ Mais informações sobre o RDF podem ser obtidas em: <https://www.w3.org/RDF>. Acesso em: 12 set. 2017.
} 
Dados Abertos (INDA) e estabelece um conjunto mínimo de elementos contendo dados necessários para recuperação e gerenciamento de informações governamentais, estabelecendo semântica entre os elementos, qualificadores e a forma de utilizá-los para descrição de conteúdos no domínio público. O e-PMG 1.1 é composto por vinte elementos e suas respectivas definições: quinze deles baseados no Padrão Dublin Core (DC), e outros cinco elementos adicionais identificados como necessários para o contexto do Governo Eletrônico brasileiro.

Os elementos que compõem o e-PMG 1.1 são: Abrangência, Assunto, Colaborador, Contexto jurídico-administrativo, Criador, Data, Descrição, Destinação, Destinatário, Direitos, Fonte, Formato, Identificador, Idioma, Localização, Preservação, Publicador, Relação, Tipo e Título.

Com relação à implantação do padrão, cada organização deve decidir quais recursos informacionais requerem os metadados e-PMG 1.1 prioritariamente. Sua implementação pode ser feita de modo gradativo, agregando coleções de recursos até reduzir a granularidade, cabendo à organização decidir quanto à necessidade de descrever os recursos já existentes (CEGE, 2014).

No guia específico do e-PMG (BRASIL, 2009), para cada elemento, são descritos os seguintes dados:

a. Nome do elemento: termo específico que nomeia o elemento;

b. Identificador: termo atribuído de acordo com o padrão original Dublin Core;

c. Definição: descrição do elemento;

d. Obrigatoriedade: grau de uso do elemento, sendo este obrigatório, obrigatório se aplicável ou opcional;

e. Objetivo: aplicabilidade do elemento;

f. Comentários: informações adicionais para compreensão e uso do elemento;

g. "Não-confundir com": apontando quais outros elementos geralmente pode gerar dúvida no momento da aplicação;

h. Qualificadores: que tornam o significado do elemento mais específico; exemplos (situações de aplicação dos elementos);

i. Sintaxe HTML: forma de uso do elemento na página HTML;

j. Esquemas: especificando a forma do elemento;

k. Mapeamento: correlação com outros padrões de metadados tradicionais.

O Quadro 2 sintetiza os dados identificados no guia do e-PMG 1.1, destacando os seguintes atributos dos elementos: nome do elemento, 
definição do elemento, obrigatoriedade e qualificadores (título e descrição).

Quadro 2 - Elementos do e-PMG 1.1 e seus principais atributos

\begin{tabular}{|c|c|c|c|c|}
\hline \multirow{2}{*}{ Nome } & \multirow{2}{*}{ Definição } & \multirow{2}{*}{$\begin{array}{l}\text { Obrigatoried } \\
\text { ade }\end{array}$} & \multicolumn{2}{|c|}{ Qualificadores } \\
\hline & & & Título & Descrição \\
\hline \multirow{2}{*}{ Abrangência } & \multirow{2}{*}{$\begin{array}{l}\text { Extensão } \\
\text { espacial e } \\
\text { temporal do } \\
\text { recurso }\end{array}$} & $\begin{array}{l}\text { Obrigatória, } \\
\text { se aplicável }\end{array}$ & abrangência.espacial & $\begin{array}{l}\text { Identificação de } \\
\text { localização geográfica }\end{array}$ \\
\hline & & $\begin{array}{l}\text { Obrigatória, } \\
\text { se aplicável }\end{array}$ & abrangência.temporal & $\begin{array}{l}\text { Indicação de datas como } \\
\text { início e fim }\end{array}$ \\
\hline \multirow[t]{3}{*}{ Assunto } & \multirow{3}{*}{\begin{tabular}{|l|} 
Palavras- \\
chave ou \\
termos que \\
representam \\
o conteúdo do \\
recurso
\end{tabular}} & Obrigatória & assunto.categoria & $\begin{array}{l}\text { Pode ser utilizado como } \\
\text { valor um termo do } \\
\text { Vocabulário Controlado do } \\
\text { Governo Eletrônico } \\
\text { (BRASIL, 2017c) que } \\
\text { esteja associado ao } \\
\text { conteúdo do recurso }\end{array}$ \\
\hline & & Opcional & assunto.palavra-chave & $\begin{array}{l}\text { Pode ser utilizado um } \\
\text { termo de qualquer outro } \\
\text { vocabulário-controlado }\end{array}$ \\
\hline & & Opacional & assunto.pessoa & $\begin{array}{l}\text { Indica quando o recurso } \\
\text { trata de uma pessoa } \\
\text { específica }\end{array}$ \\
\hline Colaborador & $\begin{array}{l}\text { Entidade que } \\
\text { contribuiu } \\
\text { para a } \\
\text { elaboração do } \\
\text { conteúdo do } \\
\text { recurso }\end{array}$ & Opcional & colaborador.papel & $\begin{array}{l}\text { Indica o papel } \\
\text { desempenhado pelo } \\
\text { colaborador na produção } \\
\text { do recurso informacional, } \\
\text { como tradutor, fotógrafo, } \\
\text { relator, revisor }\end{array}$ \\
\hline $\begin{array}{l}\text { Contexto } \\
\text { Jurídico- } \\
\text { Financeiro }\end{array}$ & $\begin{array}{l}\text { Legislação e } \\
\text { às normas } \\
\text { que regulam } \\
\text { e autorizam o } \\
\text { funcionament } \\
\text { o e o } \\
\text { desempenho } \\
\text { das } \\
\text { atividades da } \\
\text { organização } \\
\text { responsável } \\
\text { pela produção } \\
\text { e/ou } \\
\text { disponibilizaç } \\
\text { ão do recurso }\end{array}$ & Opcional & $\begin{array}{l}\text { contexto.estatutoDeAut } \\
\text { orização }\end{array}$ & $\begin{array}{l}\text { Indica a legislação que } \\
\text { autoriza a criação do } \\
\text { recurso }\end{array}$ \\
\hline \multirow[b]{2}{*}{ Criador } & \multirow{2}{*}{$\begin{array}{l}\text { Refere-se à } \\
\text { entidade } \\
\text { originalmente } \\
\text { responsável } \\
\text { pela criação e } \\
\text { manutenção } \\
\text { do recurso }\end{array}$} & Obrigatória & criador.autor & $\begin{array}{l}\text { Entidade responsável pela } \\
\text { criação do conteúdo } \\
\text { intelectual do recurso }\end{array}$ \\
\hline & & Obrigatória & criador.arquivístico & $\begin{array}{l}\text { Entidade responsável pela } \\
\text { manutenção dos recursos } \\
\text { e documentos } \\
\text { arquivísticos }\end{array}$ \\
\hline \multirow{3}{*}{ Data } & \multirow{3}{*}{$\begin{array}{l}\text { Refere-se a } \\
\text { uma data } \\
\text { associada à } \\
\text { ocorrência de } \\
\text { um evento no } \\
\text { ciclo de vida }\end{array}$} & Obrigatória & data.aceitação & $\begin{array}{l}\text { Indica quando o recurso } \\
\text { foi aceito }\end{array}$ \\
\hline & & Obrigatória & data.alteração & $\begin{array}{l}\text { Indica quando o recurso } \\
\text { foi alterado }\end{array}$ \\
\hline & & Obrigatória & data.criação & $\begin{array}{l}\text { Indica quando o recurso } \\
\text { foi criado }\end{array}$ \\
\hline
\end{tabular}




\begin{tabular}{|c|c|c|c|c|}
\hline \multirow{10}{*}{ Nome } & \multirow{10}{*}{$\begin{array}{l}\text { Definição } \\
\text { do recurso }\end{array}$} & \multirow{2}{*}{$\begin{array}{l}\text { Obrigatoried } \\
\text { ade }\end{array}$} & \multicolumn{2}{|c|}{ Qualificadores } \\
\hline & & & Título & Descrição \\
\hline & & Obrigatória & data.capturado & $\begin{array}{l}\text { Indica quando o recurso } \\
\text { foi integrado por um } \\
\text { sistema informatizado }\end{array}$ \\
\hline & & Obrigatória & data.disponibilidade & $\begin{array}{l}\text { Indica quando o recurso } \\
\text { foi disponibilizado para } \\
\text { acesso }\end{array}$ \\
\hline & & Obrigatória & data.publicação & $\begin{array}{l}\text { Indica quando o recurso } \\
\text { foi publicado }\end{array}$ \\
\hline & & Obrigatória & $\begin{array}{l}\text { data.frequênciaDeAtual } \\
\text { ização }\end{array}$ & $\begin{array}{l}\text { Indica a frequência com } \\
\text { que o recurso é atualizado }\end{array}$ \\
\hline & & Obrigatória & data.próximaVersão & $\begin{array}{l}\text { Indica quando haverá a } \\
\text { substituição do recurso por } \\
\text { um mais atualizado }\end{array}$ \\
\hline & & Obrigatória & data.recebimento & $\begin{array}{l}\text { Indica quando o recurso } \\
\text { deu entrada na } \\
\text { organização }\end{array}$ \\
\hline & & Obrigatória & data.submissão & $\begin{array}{l}\text { Indica quando o recurso } \\
\text { foi submetido à uma } \\
\text { apreciação }\end{array}$ \\
\hline & & Obrigatória & data.validade & $\begin{array}{l}\text { Indica o período máximo } \\
\text { que um recurso está valido } \\
\text { para consulta }\end{array}$ \\
\hline \multirow{2}{*}{ Descrição } & \multirow{2}{*}{$\begin{array}{l}\text { Refere-se ao } \\
\text { resumo e } \\
\text { explicação } \\
\text { sucinta do } \\
\text { conteúdo do } \\
\text { recurso }\end{array}$} & Opcional & descrição.resumo & $\begin{array}{l}\text { Consiste da exposição } \\
\text { sucinta do conteúdo do } \\
\text { recurso }\end{array}$ \\
\hline & & Opcional & descrição.sumário & $\begin{array}{l}\text { Indica a lista de } \\
\text { subunidades do conteúdo } \\
\text { do recurso }\end{array}$ \\
\hline \multirow{4}{*}{ Destinação } & \multirow{4}{*}{$\begin{array}{l}\text { Refere-se aos } \\
\text { aspectos } \\
\text { decisórios } \\
\text { quanto ao } \\
\text { encaminhame } \\
\text { nto dos } \\
\text { documentos } \\
\text { arquivísticos } \\
\text { para guarda } \\
\text { permanente } \\
\text { ou eliminação }\end{array}$} & $\begin{array}{l}\text { Obrigatória } \\
\text { para } \\
\text { documentos } \\
\text { arquivísticos } \\
\text { e Opcional } \\
\text { para os } \\
\text { demais }\end{array}$ & $\begin{array}{l}\text { destinação.dataDeAuto } \\
\text {-Remoção }\end{array}$ & $\begin{array}{l}\text { Indica a data de remoção } \\
\text { automática do recurso }\end{array}$ \\
\hline & & \begin{tabular}{|l} 
Obrigatória \\
para \\
documentos \\
arquivísticos \\
e Opcional \\
para os \\
demais \\
\end{tabular} & destinação.ação & $\begin{array}{l}\text { Descreve a ação a ser } \\
\text { realizada no recurso } \\
\text { quando determinada } \\
\text { condição for alcançada }\end{array}$ \\
\hline & & \begin{tabular}{|l|} 
Obrigatória \\
para \\
documentos \\
arquivísticos \\
e Opcional \\
para os \\
demais
\end{tabular} & $\begin{array}{l}\text { destinação.prazoDeGu } \\
\text { arda }\end{array}$ & $\begin{array}{l}\text { Indica o prazo em que o } \\
\text { recurso deve ser mantido } \\
\text { em guarda }\end{array}$ \\
\hline & & $\begin{array}{l}\text { Obrigatória } \\
\text { para } \\
\text { documentos } \\
\text { arquivísticos } \\
\text { e Opcional } \\
\text { para os } \\
\text { demais }\end{array}$ & destinação.condições & $\begin{array}{l}\text { Indica o evento que } \\
\text { dispara a contagem do } \\
\text { prazo de guarda }\end{array}$ \\
\hline
\end{tabular}




\begin{tabular}{|c|c|c|c|c|}
\hline \multirow{7}{*}{ Nome } & \multirow{7}{*}{ Definição } & \multirow{2}{*}{$\begin{array}{l}\text { Obrigatoried } \\
\text { ade }\end{array}$} & \\
\hline & & & \multicolumn{2}{|c|}{$\begin{array}{l}\text { Qualificadores } \\
\text { Deccricão }\end{array}$} \\
\hline & & $\begin{array}{l}\text { Obrigatória } \\
\text { para } \\
\text { documentos } \\
\text { arquivísticos } \\
\text { e Opcional } \\
\text { para os } \\
\text { demais } \\
\end{array}$ & destinação.data & $\begin{array}{l}\text { Indicando a data em que } \\
\text { uma ação de destinação } \\
\text { deve ser efetivada }\end{array}$ \\
\hline & & \begin{tabular}{|l|} 
Obrigatória \\
para \\
documentos \\
arquivísticos \\
e Opcional \\
para os \\
demais \\
\end{tabular} & destinação.responsável & $\begin{array}{l}\text { Idica a identidade } \\
\text { responsável pela } \\
\text { autorização da destinação }\end{array}$ \\
\hline & & \begin{tabular}{|l|} 
Obrigatória \\
para \\
documentos \\
arquivísticos \\
e Opcional \\
para os \\
demais \\
\end{tabular} & destinação.nota & $\begin{array}{l}\text { Comentários adicionais } \\
\text { sobre a ação de } \\
\text { destinação }\end{array}$ \\
\hline & & \begin{tabular}{|l|} 
Obrigatória \\
para \\
documentos \\
arquivísticos \\
e Opcional \\
para os \\
demais \\
\end{tabular} & $\begin{array}{l}\text { destinação.localDeDest } \\
\text { inação }\end{array}$ & $\begin{array}{l}\text { Indica o local previsto para } \\
\text { destinação de um recurso } \\
\text { exportado }\end{array}$ \\
\hline & & \begin{tabular}{|l|} 
Obrigatória \\
para \\
documentos \\
arquivísticos \\
e Opcional \\
para os \\
demais \\
\end{tabular} & $\begin{array}{l}\text { destinação.estágioDeE } \\
\text { xportação }\end{array}$ & $\begin{array}{l}\text { Informa sobre o } \\
\text { andamento da exportação } \\
\text { do recurso }\end{array}$ \\
\hline Destinatário & $\begin{array}{l}\text { Refere-se à } \\
\text { entidade para } \\
\text { quem a } \\
\text { informação } \\
\text { contida no } \\
\text { documento foi } \\
\text { dirigida }\end{array}$ & $\begin{array}{l}\text { Obrigatória se } \\
\text { aplicável }\end{array}$ & destinatário.cópia & $\begin{array}{l}\text { Indica o nome das } \\
\text { entidades para quem foi } \\
\text { encaminhado uma cópia } \\
\text { do recurso }\end{array}$ \\
\hline \multirow{5}{*}{ Direitos } & \multirow{5}{*}{$\begin{array}{l}\text { Refere-se às } \\
\text { restrições e } \\
\text { às } \\
\text { permissões } \\
\text { sobre o } \\
\text { acesso e o } \\
\text { uso do } \\
\text { recurso }\end{array}$} & Opcional & $\begin{array}{l}\text { direitos.classificaçãoDo } \\
\text { GrauDeSigilo }\end{array}$ & $\begin{array}{l}\text { Indica se o recurso é } \\
\text { ostensivo ou sigiloso }\end{array}$ \\
\hline & & Opcional & direitos.descritor & $\begin{array}{l}\text { Indica o significado de } \\
\text { uma marcação de } \\
\text { proteção }\end{array}$ \\
\hline & & Opcional & $\begin{array}{l}\text { direitos.dataDeExpiraçã } \\
\text { oDoGrauDeSigilo }\end{array}$ & $\begin{array}{l}\text { indica quando expira o } \\
\text { grau de sigilo do recurso }\end{array}$ \\
\hline & & Opcional & direitos.custodiador & $\begin{array}{l}\text { Indica o usuário ou função } \\
\text { com poderes de gestão } \\
\text { sobre o recurso }\end{array}$ \\
\hline & & Opcional & $\begin{array}{l}\text { direitos.listaDeAcessoD } \\
\text { osGrupos }\end{array}$ & $\begin{array}{l}\text { Indica o nome de um } \\
\text { grupo que têm direito a ter } \\
\text { acesso ao recurso }\end{array}$ \\
\hline
\end{tabular}




\begin{tabular}{|c|c|c|c|c|}
\hline \multirow{2}{*}{ Nome } & \multirow{2}{*}{ Definição } & \multirow{2}{*}{$\begin{array}{l}\text { Obrigatoried } \\
\text { ade }\end{array}$} & \multicolumn{2}{|c|}{ Qualificadores } \\
\hline & & & Título & Descrição \\
\hline Fonte & \begin{tabular}{|l|} 
Refere-se à \\
identificação \\
do recurso \\
que deu \\
origem ao \\
recurso atual \\
\end{tabular} & Opcional & $\begin{array}{l}\text { Não possui } \\
\text { qualificadores }\end{array}$ & Não possui qualificadores \\
\hline \multirow{3}{*}{ Formato } & \multirow{3}{*}{$\begin{array}{l}\text { Refere-se ao } \\
\text { conjunto de } \\
\text { característica } \\
\text { s físicas e } \\
\text { lógicas que } \\
\text { definem a } \\
\text { apresentação } \\
\text { do recurso }\end{array}$} & Opcional & $\begin{array}{l}\text { formato.formatoDeArqu } \\
\text { ivo }\end{array}$ & $\begin{array}{l}\text { Indica o formato de } \\
\text { arquivo em que o } \\
\text { conteúdo do recurso está } \\
\text { registrado } \\
\end{array}$ \\
\hline & & Opcional & formato.dimensão & $\begin{array}{l}\text { lindica o tamanho físico } \\
\text { e/ou capacidade do } \\
\text { recurso }\end{array}$ \\
\hline & & Opcional & formato.mídia & $\begin{array}{l}\text { Indicando o tipo de } \\
\text { material físico no qual o } \\
\text { recurso está persistido }\end{array}$ \\
\hline \multirow{3}{*}{ Identificador } & \multirow{3}{*}{$\begin{array}{l}\text { Aponta a } \\
\text { referência } \\
\text { inequívoca do } \\
\text { recurso em } \\
\text { um } \\
\text { determinado } \\
\text { contexto }\end{array}$} & Obrigatória & $\begin{array}{l}\text { identificador.idDoSiste } \\
\text { ma }\end{array}$ & $\begin{array}{l}\text { Indica o número gerado } \\
\text { automaticamente e } \\
\text { atribuído pelo sistema }\end{array}$ \\
\hline & & Opcional & $\begin{array}{l}\text { identificador.códigoDeC } \\
\text { lassificação }\end{array}$ & $\begin{array}{l}\text { Indica a categoria } \\
\text { atribuída para o } \\
\text { documento com base em } \\
\text { um plano de classificação }\end{array}$ \\
\hline & & $\begin{array}{l}\text { Obrigatória se } \\
\text { aplicável }\end{array}$ & identificador.versão & $\begin{array}{l}\text { Indica a versão ou edição } \\
\text { do recurso, importante } \\
\text { para verificar a existência } \\
\text { de versões anteriores }\end{array}$ \\
\hline Idiomas & $\begin{array}{l}\text { Refere-se à } \\
\text { língua em que } \\
\text { é expresso o } \\
\text { conteúdo do } \\
\text { documento }\end{array}$ & Opcional & $\begin{array}{l}\text { Não possui } \\
\text { qualificadores }\end{array}$ & Não possui qualificadores \\
\hline Localização & $\begin{array}{l}\text { Refere-se ao } \\
\text { lugar de } \\
\text { armazename } \\
\text { nto atual do } \\
\text { recurso } \\
\text { (podendo ser } \\
\text { a URL para } \\
\text { acesso ao } \\
\text { recurso no } \\
\text { repositório) }\end{array}$ & Opcional & $\begin{array}{l}\text { Não possui } \\
\text { qualificadores }\end{array}$ & Não possui qualificadores \\
\hline \multirow{5}{*}{ Preservação } & \multirow{5}{*}{$\begin{array}{l}\text { Refere-se às } \\
\text { informações } \\
\text { necessárias } \\
\text { para apoiar o } \\
\text { acesso, uso e } \\
\text { preservação } \\
\text { de longo } \\
\text { prazo de um } \\
\text { recurso }\end{array}$} & Opcional & $\begin{array}{l}\text { preservação.formatoOri } \\
\text { ginal }\end{array}$ & $\begin{array}{l}\text { Indica nome do formato } \\
\text { em que o recurso foi } \\
\text { criado }\end{array}$ \\
\hline & & Opcional & $\begin{array}{l}\text { preservação.dependên } \\
\text { ciaDeHardware }\end{array}$ & $\begin{array}{l}\text { Indica o hardware } \\
\text { necessário para acessar o } \\
\text { recurso }\end{array}$ \\
\hline & & Opcional & $\begin{array}{l}\text { preservação.dependên } \\
\text { ciaDeSoftware }\end{array}$ & $\begin{array}{l}\text { Indica o software e } \\
\text { versões necessárias para } \\
\text { acesso ao recurso }\end{array}$ \\
\hline & & Opcional & $\begin{array}{l}\text { preservação.dependên } \\
\text { ciaDeSistemaOperacio } \\
\text { nal }\end{array}$ & $\begin{array}{l}\text { Indica o sistema } \\
\text { operacional e versões } \\
\text { necessárias para acesso } \\
\text { ao recurso } \\
\end{array}$ \\
\hline & & Opcional & preservação.resolução & Descreve a resolução em \\
\hline
\end{tabular}




\begin{tabular}{|c|c|c|c|c|}
\hline \multirow{9}{*}{ Nome } & \multirow{9}{*}{ Definição } & \multirow{2}{*}{$\begin{array}{l}\text { Obrigatoried } \\
\text { ade }\end{array}$} & \multicolumn{2}{|c|}{ Qualificadores } \\
\hline & & & Título & Descrição \\
\hline & & & & formato digital \\
\hline & & Opcional & $\begin{array}{l}\text { preservação.dataDaAç } \\
\text { ão }\end{array}$ & $\begin{array}{l}\text { Indicando a data e hora } \\
\text { em que a ação de } \\
\text { preservação foi realizada }\end{array}$ \\
\hline & & Opcional & $\begin{array}{l}\text { preservação.tipoDeAçã } \\
\text { o }\end{array}$ & $\begin{array}{l}\text { Indica a ação de } \\
\text { preservação realizada }\end{array}$ \\
\hline & & Opcional & $\begin{array}{l}\text { preservação.descrição } \\
\text { DaAção }\end{array}$ & $\begin{array}{l}\text { Descreve detalhes } \\
\text { específicos da ação de } \\
\text { preservação, incluindo o } \\
\text { estado original, as } \\
\text { mudanças realizadas e os } \\
\text { motivos }\end{array}$ \\
\hline & & Opcional & $\begin{array}{l}\text { preservação.ferramenta } \\
\text { sDaAção }\end{array}$ & $\begin{array}{l}\text { Descreve as ferramentas } \\
\text { utilizadas na ação de } \\
\text { preservação }\end{array}$ \\
\hline & & Opcional & $\begin{array}{l}\text { preservação.próximaAç } \\
\text { ão }\end{array}$ & $\begin{array}{l}\text { Indica a próxima ação ou } \\
\text { avaliação da preservação } \\
\text { pela qual o recurso deve } \\
\text { passar }\end{array}$ \\
\hline & & Opcional & $\begin{array}{l}\text { preservação.dataDaPró } \\
\text { ximaAção }\end{array}$ & $\begin{array}{l}\text { Indica quanto haverá } \\
\text { próxima ação ou avaliação } \\
\text { da preservação pela qual } \\
\text { o recurso deve passar } \\
\end{array}$ \\
\hline Publicador & \begin{tabular}{|l|} 
Refere-se à \\
entidade \\
responsável \\
por tornar o \\
recurso \\
disponível \\
\end{tabular} & $\begin{array}{l}\text { Obrigatória se } \\
\text { aplicável }\end{array}$ & $\begin{array}{l}\text { Não possui } \\
\text { qualificadores }\end{array}$ & Não possui qualificadores \\
\hline \multirow{7}{*}{ Relação } & \multirow{7}{*}{$\begin{array}{l}\text { Diz respeito à } \\
\text { referência ou } \\
\text { associação } \\
\text { que o recurso } \\
\text { descrito } \\
\text { possui } \\
\text { perante outro } \\
\text { recurso } \\
\text { existente }\end{array}$} & Opcional & $\begin{array}{l}\text { relação.conformidadeC } \\
\text { om }\end{array}$ & $\begin{array}{l}\text { Indica a referência a um } \\
\text { padrão estabelecido pelo } \\
\text { qual o recurso está em } \\
\text { conformidade } \\
\end{array}$ \\
\hline & & Opcional & $\begin{array}{l}\text { relação.descriçãoDaRel } \\
\text { ação }\end{array}$ & $\begin{array}{l}\text { Destaca a relação entre } \\
\text { dois ou mais recursos }\end{array}$ \\
\hline & & Opcional & relação.éFormatoDe & $\begin{array}{l}\text { Indica a referência ao } \\
\text { formato do recurso que } \\
\text { deu origem ao recurso } \\
\text { descrito } \\
\end{array}$ \\
\hline & & Opcional & relação.éParteDe & $\begin{array}{l}\text { Indica partes físicas ou } \\
\text { lógicas do recurso } \\
\text { referenciado }\end{array}$ \\
\hline & & Opcional & $\begin{array}{l}\text { relação.éReferenciado } \\
\text { Por }\end{array}$ & $\begin{array}{l}\text { Indica se o recurso } \\
\text { descrito é citado ou } \\
\text { apontado por outro } \\
\text { recurso }\end{array}$ \\
\hline & & Opcional & relação.éRequeridoPor & $\begin{array}{l}\text { Indica se o recurso } \\
\text { descrito é requerido para } \\
\text { apoiar a utilização ou } \\
\text { manter a coerência do } \\
\text { conteúdo de outro recurso } \\
\text { relacionado }\end{array}$ \\
\hline & & Opcional & $\begin{array}{l}\text { relação.éSubstituídoPo } \\
\text { r }\end{array}$ & $\begin{array}{l}\text { Indica se o recurso } \\
\text { descrito foi substituído por } \\
\text { algum outro recurso }\end{array}$ \\
\hline
\end{tabular}




\begin{tabular}{|c|c|c|c|c|}
\hline \multirow{2}{*}{ Nome } & \multirow{2}{*}{ Definição } & \multirow{2}{*}{$\begin{array}{l}\text { Obrigatoried } \\
\text { ade }\end{array}$} & \multicolumn{2}{|c|}{ Qualificadores } \\
\hline & & & Título & Descrição \\
\hline & & Opcional & relação.éVersãoDe & $\begin{array}{l}\text { Indica se o recurso } \\
\text { descrito é uma edição, } \\
\text { versão, ou adaptação de } \\
\text { outro recurso }\end{array}$ \\
\hline & & Opcional & $\begin{array}{l}\text { relação.razãoDaTarjaO } \\
\text { uTruncamento }\end{array}$ & $\begin{array}{l}\text { Descreve a razão para a } \\
\text { publicação de um } \\
\text { truncamento, como } \\
\text { privacidade ou sigilo }\end{array}$ \\
\hline & & Opcional & relação.referência & $\begin{array}{l}\text { Indica se o recurso } \\
\text { descrito cita ou aponta } \\
\text { outro recurso relacionado }\end{array}$ \\
\hline & & Opcional & relação.requer & $\begin{array}{l}\text { Indica se o recurso } \\
\text { descrito necessita de outro } \\
\text { recurso para assegurar } \\
\text { sua inteligibilidade }\end{array}$ \\
\hline & & Opcional & relação.substitui & $\begin{array}{l}\text { Indica se o recurso } \\
\text { substitui um recurso } \\
\text { anterior }\end{array}$ \\
\hline & & Opcional & $\begin{array}{l}\text { relação.tarjaOuTrunca } \\
\text { mento }\end{array}$ & $\begin{array}{l}\text { Indica se o recurso } \\
\text { descrito possui uma } \\
\text { versão com alguma parte } \\
\text { de conteúdo removida }\end{array}$ \\
\hline & & Opcional & relação.temFormatoDe & $\begin{array}{l}\text { Indica se o recurso possui } \\
\text { outros formatos }\end{array}$ \\
\hline & & Opcional & relação.temParteDe & $\begin{array}{l}\text { Indica se o recurso } \\
\text { descrito tem parte de outro } \\
\text { recurso relacionado }\end{array}$ \\
\hline & & Opcional & relação.temVersãoDe & $\begin{array}{l}\text { Indica se o recurso } \\
\text { descrito tem outras } \\
\text { versões ou edições }\end{array}$ \\
\hline $\begin{array}{l}\text { Tipo de } \\
\text { Recurso }\end{array}$ & $\begin{array}{l}\text { Refere-se à } \\
\text { natureza ou } \\
\text { gênero do } \\
\text { conteúdo } \\
\text { presente no } \\
\text { recurso }\end{array}$ & $\begin{array}{l}\text { Obrigatória se } \\
\text { aplicável }\end{array}$ & $\begin{array}{l}\text { Não possui } \\
\text { qualificadores }\end{array}$ & Não possui qualificadores \\
\hline Título & $\begin{array}{l}\text { Refere-se à } \\
\text { uma palavra, } \\
\text { frase ou } \\
\text { grupo de } \\
\text { caracteres } \\
\text { que nomeia } \\
\text { um recurso e } \\
\text { que pode } \\
\text { corresponder } \\
\text { à sua } \\
\text { denominação } \\
\text { oficial }\end{array}$ & $\begin{array}{l}\text { Obrigatória, } \\
\text { mas Opcional } \\
\text { para título } \\
\text { alternativo }\end{array}$ & título.títuloAlternativo & $\begin{array}{l}\text { Título substituto ou outra } \\
\text { forma de designar um } \\
\text { recurso, podendo ser o } \\
\text { título oficial em outro } \\
\text { idioma }\end{array}$ \\
\hline
\end{tabular}

Fonte: Adaptação de CEGE (2014).

\section{Resultados}

Para compor os resultados desta pesquisa, foram estudados os datasets disponibilizados pelo Portal Brasileiro de Dados Abertos, sendo analisada a representação dos recursos informacionais por meio da 
identificação dos elementos de metadados apresentados durante o processo de recuperação realizado por meio de pesquisas via buscador interno do Portal.

Na Figura 1 é apresentado um esquema com a estrutura padrão dos datasets analisados no Portal Brasileiro de Dados Abertos, destacando os principais componentes do conteúdo da página.

A maioria dos elementos de metadados descritivos do dataset está apresentada na área localizada na parte inferior do recurso. Contudo, no topo, verificam-se metadados como Título e Descrição. Para poder associar os elementos de metadados identificados nos datasets com os elementos do e-PMG 1.1 utilizou-se a técnica Crosswalking, adotando critérios como a observação da terminologia dos metadados apresentados, a verificação do conteúdo referente aos valores dos elementos e as diretrizes de aplicação verificadas no guia oficial do e-PMG 1.1.

O Título do dataset pode ser associado ao elemento "título" do ePMG 1.1, de aplicação obrigatória. Este metadado foi verificado em todos os datasets analisados durante a pesquisa e é utilizado para denominar um recurso e permitir sua identificação.

O conjunto de texto localizado logo abaixo do Título descreve o conteúdo presente naquele dataset, e a partir do Crosswalk pode ser associado ao elemento "descrição" do e-PMG 1.1 e seu qualificador "descrição.resumo", de aplicação opcional. Este metadado foi verificado na descrição de todos os datasets analisados durante a pesquisa, e é utilizado para realizar uma exposição sucinta do conteúdo do recurso.

Os termos que resumem o assunto abordado por cada dataset, localizados após a lista de recursos informacionais disponíveis no dataset, a partir do Crosswalk podem ser associados ao elemento "assunto" do ePMG 1.1 e seu qualificador "assunto.palavra-chave", de aplicação opcional. Este metadado foi verificado na descrição de todos os datasets analisados durante a pesquisa, e é utilizado para descrever de forma precisa os termos de interesse presentes no recurso informacional utilizando um vocabulário controlado, no caso, o Vocabulário Controlado do Governo Eletrônico.

Figura 1 - Estrutura padrão dos datasets no Portal Brasileiro de Dados Abertos

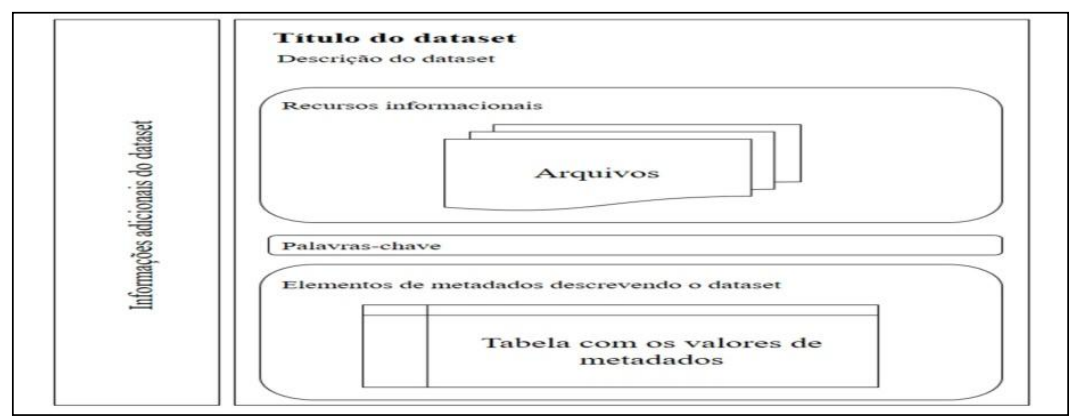

Fonte: Os autores. 
Na área localizada na parte inferior da página (ilustrado na Figura 1) foram verificados um conjunto de elementos de metadados descrevendo informações adicionais do recurso. Contudo, nem todos os elementos estavam apresentados na descrição dos datasets analisados (a frequência com que cada elemento de metadado constava na página pode ser observada na Tabela 1 ).

O elemento "Autor", a partir do Crosswalk, pode ser associado ao elemento "criador" do e-PMG 1.1 e seu qualificador "criador.autor", de aplicação obrigatória. Este metadado foi verificado na descrição de todos os datasets analisados durante a pesquisa e apresentava valores referentes ao nome de entidades responsáveis pela criação do conteúdo intelectual disponível pelo dataset (ex: Secretária Básica de Saúde).

O elemento "Mantenedor", a partir do Crosswalking, pode ser associado ao elemento "criador" do e-PMG 1.1 e seu qualificador "criador.produtor", de aplicação obrigatória. Este metadado foi verificado na descrição de todos os datasets analisados durante a pesquisa e apresentava valores referentes ao nome de entidades responsáveis pela manutenção e proteção dos recursos contendo o conteúdo intelectual disponível pelo dataset (ex: Gabinete do Ministro).

O elemento "Fonte", a partir do Crosswalking, pode ser associado ao elemento "fonte" do e-PMG 1.1, de aplicação opcional. Este metadado foi verificado na descrição de $96 \%$ dos datasets analisados durante a pesquisa e tem como função identificar uma fonte específica que deu origem ao recurso atual. Este elemento apresentava como valor um hiperlink apontando para o portal da entidade originária do dataset (ex: http://pgi.gov.br/pgi/).

O elemento "Órgão - Poder" não pode ser associado a nenhum elemento do e-PMG 1.1. Este metadado foi verificado na descrição de $92 \%$ dos datasets analisados durante a pesquisa e apresentava como valor um termo indicando o nível de poder relacionado às entidades responsáveis pelo dataset (ex: Executivo).

O elemento "Órgão - Esfera" não pode ser associado a nenhum elemento do e-PMG 1.1. Este metadado foi verificado na descrição de $88 \%$ dos datasets analisados durante a pesquisa e apresentava como valor um termo indicando a esfera relacionada às entidades responsáveis pelo dataset (ex: Federal).

O elemento "Granularidade geográfica", a partir do Crosswalking, pode ser associado ao elemento "abrangência" do e-PMG 1.1 e seu qualificador "abrangência.espacial", de aplicação obrigatória se aplicável. Este metadado foi verificado na descrição de $88 \%$ dos datasets analisados durante a pesquisa e apresentava como valor termos indicando nível de detalhamento espacial do conjunto de dados presente no dataset analisado (ex: estadual).

O elemento "Frequência de atualização", a partir do Crosswalking, pode ser associado ao elemento "data" do e-PMG 1.1 e seu qualificador "data.frequênciaDeAtualização", de aplicação obrigatória. Este metadado foi verificado na descrição de $52 \%$ dos datasets analisados durante a 
pesquisa e apresentava como valor termos indicando frequência de atualização do dataset (ex: anual, mensal, diário).

O elemento "Assuntos", a partir do Crosswalking, pode ser associado ao elemento "assunto" do e-PMG 1.1 e seu qualificador "assunto.categoria", de aplicação obrigatória. Este metadado foi verificado na descrição de $28 \%$ dos datasets analisados durante a pesquisa e apresentava como valores termos apontando categorias específicas relacionadas ao assunto contido naquele dataset (ex: Unidade Básica de Saúde).

O elemento "VCGE" não pode ser associado a nenhum elemento do e-PMG 1.1. Este metadado foi verificado na descrição de $28 \%$ dos datasets analisados durante a pesquisa e complementava os termos do elemento "Assuntos" com um hiperlink apontando para o website no qual são disponibilizadas as relações de termos do Vocabulário Controlado do Governo Eletrônico (ex: Unidade básica de saúde [http://vocab.e.gov.br/2011/03/vcge\#unidade-basica-saude]).

O elemento "Spatial" não pode ser associado a nenhum elemento do e-PMG 1.1. Este metadado foi verificado na descrição de $16 \%$ dos datasets analisados durante a pesquisa e apresentava como valores termos estruturados em formato de coordenadas geográficas (ex: "type":"Polygon", "coordinates":[[[-74.0046,-33.7411],[-34.7929,33.7411],[-34.7929,5.27271],[-74.0046,5.27271],[-74.0046,33.7411]]]).

O elemento "Atualidade" não pode ser associado a nenhum elemento do e-PMG 1.1. Este metadado foi verificado na descrição de $16 \%$ dos datasets analisados durante a pesquisa e apresentava como valor a data indicando a última atualização do dataset (ex: 14-04-2016).

O elemento "Cobertura geográfica" não pode ser associado a nenhum elemento do e-PMG 1.1. Este metadado foi verificado na descrição de $8 \%$ dos datasets analisados durante a pesquisa e apresentava como valor termos identificando a localização do conjunto de dados presente no dataset (ex: Brasil).

O elemento "Granularidade Temporal", a partir do Crosswalking, pode ser associado ao elemento "abrangência" do e-PMG 1.1 e seu qualificador "abrangência.temporal", de aplicação obrigatória se aplicável. Este metadado foi verificado na descrição de $8 \%$ dos datasets analisados durante a pesquisa e apresentava como valor termos indicando o nível de detalhamento temporal do conjunto de dados presente no dataset (ex: anual).

$\mathrm{Na}$ Tabela 1 estão sistematizados os elementos de metadados descritivos identificados nos datasets observados no Portal Brasileiro de Dados Abertos, acompanhados pelo grau de frequência com que cada elemento apresentou-se durante o processo de recuperação. Para cada elemento identificado, a tabela aponta o elemento de metadado do e-PMG 1.1 no qual o mesmo pode ser associado, assim como o grau de obrigatoriedade de sua aplicação conforme disposto no guia oficial. 
Tabela 1 - Elementos de metadados descritivos do dataset e relação com elementos de metadados do e-PMG

\begin{tabular}{c|c|c|c}
\hline Metadados do Dataset & Elementos do e-PMG 1.1 & Obrigatoriedade & $\begin{array}{c}\text { Presença em } \\
\text { datasets }\end{array}$ \\
\hline \hline Título do Dataset & título & Obrigatório & $100 \%$ \\
\hline Descrição do Dataset & descrição.resumo & Opcional & $100 \%$ \\
\hline Palavras-chave & assunto.palavra-chave & Opcional & $100 \%$ \\
\hline Autor & criador.autor & Obrigatório & $100 \%$ \\
\hline Mantenedor & criador.produtor & Obrigatório & $100 \%$ \\
\hline Fonte & fonte & Opcional & $96 \%$ \\
\hline Órgão-Poder & Não encontrado & Não encontrado & $92 \%$ \\
\hline Órgão-Esfera & Não encontrado & Não encontrado & $88 \%$ \\
\hline Granularidade Geográfica & abrangência.espacial & Obrigatório, se & aplicável \\
\hline Frequência de atualização & data.frequênciaDeAtualização & Obrigatório & $56 \%$ \\
\hline Assuntos & assunto.categoria & Obrigatório & $28 \%$ \\
\hline VCGE & Não encontrado & Não encontrado & $28 \%$ \\
\hline Spatial & Não encontrado & Não encontrado & $16 \%$ \\
\hline Atualidade & Não encontrado & Não encontrado & $16 \%$ \\
\hline Cobertura Geográfica & Não encontrado & Não encontrado & $8 \%$ \\
\hline Granularidade Temporal & abrangência.temporal & Obrigatório, se & aplicável \\
\hline
\end{tabular}

Fonte: Os autores.

Observa-se, na Tabela 1, que elementos como "Título", "Descrição", "Palavras-chave", "Autor" e "Mantenedor", constavam em todos os datasets analisados. Contudo, elementos como "Fonte", "Órgão - Poder", "Órgão - Esfera", "Granularidade geográfica", "Frequência de atualização", "Assuntos", "VCGE", "Spatial", "Atualidade", "Cobertura geográfica" e "Granularidade temporal", não constavam em todos os datasets analisados, mesmo quando definida a sua obrigatoriedade.

Por meio dos datasets presentes no Portal Brasileiro de Dados Abertos são disponibilizados recursos informacionais contendo arquivos com o conjunto de dados e/ou serviços de visualização. Ao selecionar um recurso presente em determinado dataset o usuário é direcionado para uma página contendo outros elementos de metadados descritivos relacionados especificamente ao arquivo contendo os dados, ou seja, ao recurso informacional, e não ao dataset no qual o mesmo é disponibilizado.

$\mathrm{Na}$ Figura 2, é apresentada a estrutura padrão dos recursos informacionais contidos nos datasets acessíveis pelo Portal Brasileiro de Dados Abertos. $\mathrm{Na}$ área inferior da página, apresentam-se os metadados descritivos do recurso informacional e, no topo da página, localizam-se outros elementos como "Título" e "Descrição" do conjunto de dados. Além da apresentação de elementos de metadados descritivos, na área central, é possível visualizar o conjunto de dados presentes no arquivo.

O elemento "Título", a partir do Crosswalking, pode ser associado ao elemento "título" do e-PMG 1.1, de aplicação obrigatória. Este metadado foi verificado na descrição de todos os recursos informacionais 
disponibilizados nos datasets analisados e é utilizado para denominar um recurso permitindo sua localização.

O conjunto de texto complementando o "Título" no topo da página e descrevendo o conteúdo dos dados presentes no arquivo de forma resumida, a partir do Crosswalking, pode ser associado ao elemento "descrição" do e-PMG 1.1 e seu qualificador "descrição.resumo", de aplicação opcional. Este metadado foi verificado na descrição de todos os recursos informacionais disponibilizados nos datasets analisados e é utilizado para realizar uma exposição sucinta do conteúdo.

Com relação aos elementos de metadados apresentados na área inferior do recurso informacional, o elemento "Última atualização" não pode ser associado a nenhum elemento e-PMG 1.1. Este metadado foi verificado na descrição de todos os recursos informacionais disponibilizados nos datasets analisados e apresentava como valor a data indicando a última atualização do arquivo contendo o conjunto de dados (ex:24/Setembro/2016).

Figura 2 - Estrutura padrão dos recursos informacionais nos datasets acessíveis pelo Portal Brasileiro de Dados Abertos

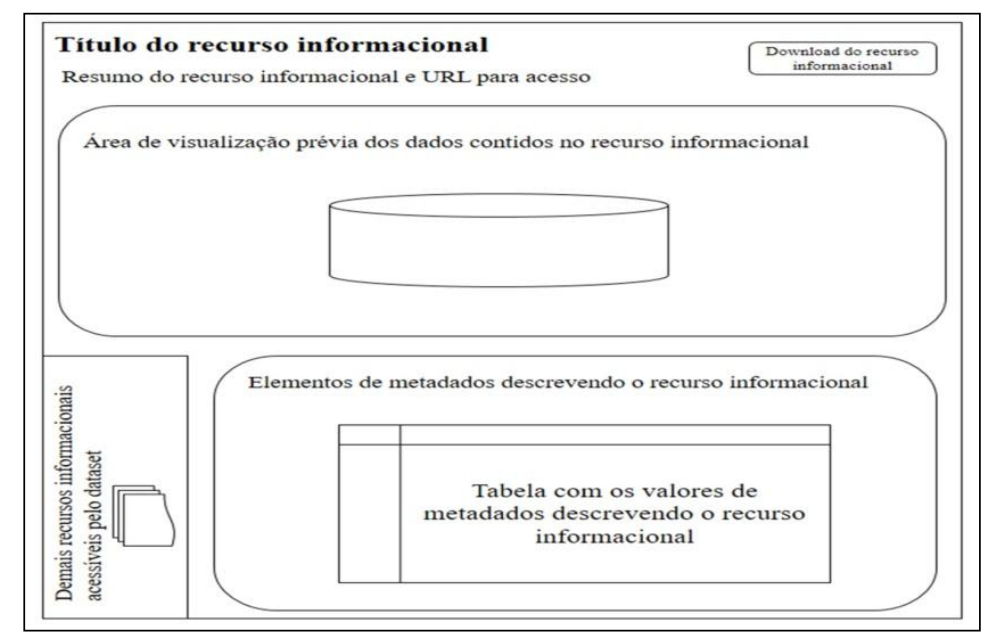

Fonte: Os autores.

O elemento "Criado", a partir do Crosswalking, pode ser associado ao elemento "data" do e-PMG 1.1 e seu qualificador "data.criação", de aplicação obrigatória. Este metadado foi verificado na descrição de todos os recursos informacionais disponibilizados nos datasets analisados e apresentava como valor a data referente à data de criação do recurso contendo o conjunto de dados (ex: 24/Setembro/2016).

O elemento "Formato", a partir do Crosswalking, pode ser associado ao elemento "formato" do e-PMG 1.1 e seu qualificador "formato.formatoDeArquivo", de aplicação opcional. Este metadado foi verificado na descrição de todos os recursos informacionais disponibilizados nos datasets analisados e apresentava como valor a denominação do formato de arquivo contendo o conjunto de dados (ex: $X M L$, JSON, PDF). 
O elemento "Licença" não pode ser associado a nenhum elemento do e-PMG 1.1. Este metadado foi verificado na descrição de todos os recursos informacionais disponibilizados nos datasets analisados $\mathrm{e}$ apresentava como valor termos indicando qual a licença utilizada para acesso ao arquivo contendo o conjunto de dados (ex: Licença Aberta para Bases de Dados do Open Data Commons).

O elemento "format" não pode ser associado a nenhum elemento do e-PMG 1.1. Este metadado foi verificado na descrição de todos os recursos informacionais disponibilizados nos datasets analisados e apresentava como valor o mesmo resultado do elemento "Formato", referindo-se à denominação do formato de arquivo contendo o conjunto de dados (ex: XML, JSON, PDF).

O elemento "id", a partir do Crosswalking, pode ser associado ao elemento "identificador" do e-PMG 1.1 e seu qualificador "identificador.idDoSistema", de aplicação obrigatória. Este metadado foi verificado na descrição de todos os recursos informacionais disponibilizados nos datasets analisados e apresentava como valor um conjunto de caracteres gerados automaticamente pelo sistema para identificação unívoca do recurso (ex: 91b8af2e-07a1-4952-932d13d941d82733).

O elemento "mime type" não pode ser associado a nenhum elemento do e-PMG 1.1. Este metadado foi verificado na descrição de todos os recursos informacionais disponibilizados nos datasets analisados e apresentava como valor o mesmo valor dos elementos "Formato" e "format", indicando o formato de arquivo contendo o conjunto de dados (ex: XML, JSON, PDF).

O elemento "resource group id", a partir do Crosswalking, pode ser associado ao elemento "identificador" do e-PMG 1.1 e seu qualificador "identificador.códigoDeClassificação", de aplicação opcional. Este metadado foi verificado na descrição de todos os recursos informacionais disponibilizados nos datasets analisados e apresentava como valor um conjunto de caracteres atribuídos pelo sistema possivelmente para identificação do recurso em um plano de classificação específica para grupos (ex: e7e5e1e1-b35f-4525-95cd-069df00222e5).

O elemento "revision id" não pode ser associado a nenhum elemento do e-PMG 1.1. Este metadado foi verificado na descrição de todos os recursos informacionais disponibilizados nos datasets analisados $\mathrm{e}$ apresentava como valor um conjunto de caracteres atribuídos pelo sistema para identificação do recurso (ex: b5f53d60-5397-4b67-af0925f74e1d4767).

O elemento "state" não pode ser associado a nenhum elemento do e-PMG 1.1. Este metadado foi verificado na descrição de todos os recursos informacionais disponibilizados nos datasets analisados durante a pesquisa e apresentava como valor uma indicação da condição de acesso ao recurso (ex: active, inactive).

O elemento "position" não pode ser associado a nenhum elemento do e-PMG 1.1. Este metadado foi verificado na descrição de $92 \%$ dos 
recursos informacionais disponibilizados nos datasets analisados durante a pesquisa e apresentava como valor um número inteiro indicando referência sequencial da ordem dos arquivos acessíveis em determinado dataset (ex: position 2).

O elemento "can be previewed" não pode ser associado a nenhum elemento do e-PMG 1.1. Este metadado foi verificado na descrição de $84 \%$ dos recursos informacionais disponibilizados nos datasets analisados durante a pesquisa e apresentava como valor um número booleano indicando a possibilidade de pré-visualizar o recurso ou não (ex: 0 ou 1).

O elemento "created" não pode ser associado a nenhum elemento do e-PMG 1.1. Este metadado foi verificado na descrição de $84 \%$ dos recursos informacionais disponibilizados nos datasets analisados e apresentava como valor a quantidade de dias decorrentes da data de criação do arquivo contendo o conjunto de dados (ex: há mais de um ano, 20 dias).

O elemento "webstore url", a partir do Crosswalking, pode ser associado ao elemento "localização" do e-PMG 1.1, de aplicação opcional. Este metadado foi verificado na descrição de $56 \%$ dos recursos informacionais disponibilizados nos datasets analisados e apresenta como valor um endereço eletrônico apontando para o local de armazenamento do recurso.

O elemento "mime type inner" não pode ser associado a nenhum elemento do e-PMG 1.1. Este metadado foi verificado na descrição de $24 \%$ dos recursos informacionais disponibilizados nos datasets analisados. Assim como os elementos "Formato", "format" e "mime type", este metadado também apresenta como valor a denominação referente ao formato de arquivo contendo o conjunto de dados ( $X M L, J S O N, P D F)$.

O elemento "resource type", a partir do Crosswalking, pode ser associado ao elemento "tipo de recurso" do e-PMG 1.1, de aplicação obrigatória se aplicável. Este metadado foi verificado na descrição de $24 \%$ dos recursos informacionais disponibilizados nos datasets analisados e apresenta como valor a natureza do tipo de conjunto de dados (ex: file, map).

O elemento "size", a partir do Crosswalking, pode ser associado ao elemento "formato" do e-PMG 1.1 e seu qualificador "formato.dimensão", de aplicação opcional. Este metadado foi verificado na descrição de $4 \%$ dos recursos informacionais disponibilizados nos datasets analisados e como valor recebia indicação de tamanho físico ou capacidade do recurso (ex: 105 bytes). 
Tabela 2 - Metadados descritivos dos recursos informacionais acessíveis pelos datasets e relação com elemento do e-PMG

\begin{tabular}{c|c|c|c}
\hline $\begin{array}{c}\text { Metadados dos recursos } \\
\text { informacionais }\end{array}$ & Elementos do e-PMG 1.1 & Obrigatoriedade & $\begin{array}{c}\text { Presença } \\
\text { em } \\
\text { datasets }\end{array}$ \\
\hline \hline Título & título & Obrigatório & $100 \%$ \\
\hline Resumo & descrição.resumo & Opcional & $100 \%$ \\
\hline Última atualização & Não encontrado & Não encontrado & $100 \%$ \\
\hline Criado & data.criação & Obrigatório & $100 \%$ \\
\hline Formato & formato.formatoDeArquivo & Opcional & $100 \%$ \\
\hline Licença & Não encontrado & Não encontrado & $100 \%$ \\
\hline format & Não encontrado & Obrigatório & $100 \%$ \\
\hline Id & identificador.idDoSistema & Não encontrado & $100 \%$ \\
\hline mimetype & Não encontrado & Opcional & $100 \%$ \\
\hline resource group id & identificador.códigoDeClassificação & Não encontrado & $100 \%$ \\
\hline revision id & Não encontrado & Não encontrado & $100 \%$ \\
\hline state & Não encontrado & Não encontrado & $92 \%$ \\
\hline position & Não encontrado & Não encontrado & $84 \%$ \\
\hline can be previewed & Não encontrado & Não encontrado & $84 \%$ \\
\hline created & Não encontrado & Opcional & $56 \%$ \\
\hline Webstore url & localização & Não encontrado & $24 \%$ \\
\hline mimetype inner & Não encontrado & Obrigatório, se & \\
\hline resource type & aplicável & $24 \%$ \\
\hline size & tipo de recurso & Opcional & $4 \%$ \\
\hline
\end{tabular}

Fonte: Os autores.

Observa-se na Tabela 2 que elementos como "Título", "Resumo do conjunto de dados", "URL", "Última atualização", "Criado", "Formato", "Licença", "format", "id", "mime type", "resource group id", "revision id" e "state", constavam em todos os recursos informacionais acessíveis nos datasets. Contudo, elementos como "position", "can be previewed", "created", "webstore url", "mime type inner", "resource type" e "size" não constavam em todos os recursos informacionais acessíveis pelos datasets.

Alguns metadados identificados, que descreviam os recursos informacionais disponibilizados nos datasets analisados, ao serem associados com elementos do e-PMG 1.1 podem ser considerados ambíguos, como nos casos de "Criado" e "created", onde ambos os metadados referem-se à data de criação do arquivo, diferenciando-se, apenas, na forma de representação dos valores. Outro caso que também pode gerar ambiguidade refere-se aos elementos "Formato", "format", "mime type" e "mime type inner", que também recebiam o mesmo valor referente à descrição do formato de arquivo.

\section{Considerações finais}

O uso da Web pode ampliar os horizontes do compartilhamento de informações governamentais, viabilizado maior interação entre administração pública (no fornecimento de serviços mais eficientes) e 
sociedade (na busca de conteúdos para participação e controle das ações do Governo).

Esta pesquisa descreve o cenário da disponibilização de dados governamentais na $W e b$, analisando a descrição dos datasets e recursos informacionais acessíveis pelo Portal Brasileiro de Dados Abertos, sendo possível verificar a frequência com que os elementos de metadados eram apresentados durante o processo de recuperação.

Por meio de um Crosswalk abrangendo os elementos de metadados identificados nos datasets e nos recursos informacionais disponibilizados pelo Portal Brasileiro de Dados Abertos, e associando-os aos elementos de metadados do e-PMG 1.1, foi possível apontar relações de similaridade e diferença entre eles.

Alguns pontos relacionados à apresentação dos elementos de metadados descrevendo os datasets e os recursos informacionais analisados merecem ser destacados, como a inconsistência na apresentação de elementos que puderam ser associados a metadados do e-PMG 1.1 de aplicabilidade obrigatória ("Frequência de atualização" e "Assuntos" na descrição dos datasets) e obrigatória se aplicável ("Granularidade Geográfica" e "Granularidade Temporal" na descrição dos datasets e "resource type" na descrição dos recursos informacionais).

Com base nestes pontos apresentados, questiona-se o porquê da não utilização do e-PMG 1.1 de forma completa no Portal Brasileiro de Dados Abertos, uma vez que este padrão é específico para a descrição de recursos governamentais. Entende-se que deve haver maiores esforços por parte das organizações governamentais na consolidação da aplicação deste padrão, visto que a padronização da representação dos recursos informacionais impacta diretamente no processo de recuperação da informação em ambientes abertos.

\section{Referências}

ALVES, R. C. V. Web semântica: uma análise focada no uso de metadados. 2005. 180f. Dissertação (Mestrado em Ciência da Informação) - Faculdade de Filosofia e Ciências, Universidade Estadual Paulista, Marília, 2005.

ANDERSEN, K. V.; HENRIKISEN. H. Z. E-government maturity models: extension of the Layne and Lee model. Government Information Quarterly, v. 23, n. 1, p. 236-248, 2006. Disponível em: $<$ http://www.sciencedirect.com/science/article/pii/S0740624X05000973>. Acesso em: 20 fev. 2015.

BACA, M. Introduction to metadata. 2 ed. Los Angeles: Getty Research Institute, 2008.

BRASIL. Comitê Executivo de Governo Eletrônico. Padrão de metadados do governo eletrônico: e-PMG. 2009. Disponível em: <http://www.governoeletronico.gov.br/documentos-e-arquivos/e-PMG\%20V0.pdf>.

Acesso em: 24 abr. 2016. 
BRASIL. Presidência da República. Lei no 12.527 , de 18 de novembro de 2011. Regula o acesso a informações previsto no inciso XXXIII do art. 5o, no inciso II do § 30 do art. 37 e no § 20 do art. 216 da Constituição Federal; altera a Lei no 8.112, de 11 de dezembro de 1990; revoga a Lei no 11.111, de 5 de maio de 2005, e dispositivos da Lei no 8.159, de 8 de janeiro de 1991; e dá outras providências. DOU, Brasília, ed. extra, 18 nov. 2011. Disponível em: <http://www.planalto.gov.br/ccivil 03/ Ato20112014/2011/Lei/L12527.htm >. Acesso em: 24 abr. 2016.

BRASIL. Sobre o dados.gov.br. Governo Federal, 2016. Disponível em: < http://dados.gov.br/sobre/>. Acesso em: 24 abr. 2016.

BRASIL. Ministério da Transparência; Controladoria Geral da União. Portal da transparência. 2017a. Disponível em: <http://transparencia.gov.br>. Acesso em: 1 maio 2017.

BRASIL. Secretaria de Tecnologia da Informação; Ministério do Planejamento, Desenvolvimento e Gestão. Portal brasileiro de dados abertos. 2017b. Disponível em: <http://dados.gov.br>. Acesso em: 1 maio 2017.

BRASIL. Repositório de vocabulários e ontologias do governo eletrônico. 2017c. Disponível em: <http://vocab.e.gov.br/>. Acesso em: 1 maio 2017.

COMITÊ EXECUTIVO DO GOVERNO ELETRÔNICO (CEGE). Padrão de metadados do Governo Eletrônico (e-PMG 1.1). CEGE, 2014. Disponível em: $\quad<$ http://www.governoeletronico.gov.br/biblioteca/arquivos/e-PMG 1.1 versao 1 1>. Acesso em: 24 abr. 2016.

CONTROLADORIA GERAL DA UNIÃO (CGU). Esclarecimentos sobre atuação e funcionamento da Parceria para Governo Aberto (OGP) no Brasil. CGU, 2016. Disponível em: < http://www.governoaberto.cgu.gov.br/nobrasil/perguntas-frequentes>. Acesso em: 24 abr. 2016.

FERNANDES, A. M. R. Inteligência artificial: noções gerais. Florianópolis: VisualBooks, 2005.

FOULONNEAU, M.; RILEY, J. Choosing metadata standards for a digital library project. In: FOULONNEAU, M.; RILEY, J. Metadata for digital resources: implementation, systems design and interoperability. Oxford: Chandos, 2008. p. 13-28.

HAWKINS, D.T. Information science abstracts: tracking the literature of information science. Part 1: definition and map. Journal of the American Society for Information Science and Technology, v. 52, p. 44-54. 2001. Disponível em: <http://onlinelibrary.wiley.com/doi/10.1002/15322890(2000)52:1\%3C44::AID-ASI1057\%3E3.0.CO;2-6/epdf>. Acesso em: 4 abr. 2016.

LEVY, A. Y. Logic-based techniques in data integration. In: MINKER, J. (Ed.) Logic-based artificial intelligence. Norwell, MA: Kluwer Academic Publisher, 2000. p. 575-595. Disponível em: 
<http://rakaposhi.eas.asu.edu/cse494/notes/levy-di00.pdf >. Acesso em: 14 abr. 2016.

MARTINES USERO, J. A. Nuevas tecnologías para nuevas bibliotecas: desarrollo de servicios de informacíon electrónica. Buenos Aires: Alfagrama Ediciones, 2007.

MEY, E. S. A. Introdução a catalogação. Brasília: Briquet de Lemos, 1995.

MOURA, A. M. de C.; FERNANDES, C. S. A Metadata approach to represent and visualize sites on the web. In: INTERNATIONAL WORKSHOP ON INFORMATION INTEGRATION TECHNOLOGIES ON THE WEB, n.1, Itaipava, 2001. Anais eletrônicos... Itaipava, RJ, 9-11 abril 2001. Disponível em: $<$ http://www.lbd.dcc.ufmg.br/bdbcomp/servlet/Trabalho?id=1649>. Acesso em: 20 abr. 2016.

PLATT NETO, O. A. P.; CRUZ, F. da; VIEIRA, A. L. Transparência das contas públicas: um enfoque no uso da internet como instrumento de publicidade na UFSC. Revista Contemporânea de Contabilidade, v. 1, n. 5, p. 135-146, 2006. Disponível em: $<$ https://periodicos.ufsc.br/index.php/contabilidade/article/view/1143>. Acesso em: 6 abr. 2016.

SANT'ANA, R. C. G. Tecnologia e gestão pública municipal: mensuração da interação com a sociedade. São Paulo: Cultura Acadêmica Editora UNESP, 2009. v. 1.

SANT'ANA. R. C. G. Ciclo de vida dos dados e o papel da Ciência da Informação. In: ENCONTRO NACIONAL DE PESQUISA EM CIÊNCIA DA INFORMAÇÃO (ENANCIB), 14., Florianópolis, 2013. Anais eletrônicos... Florianópolis: ANCIB, 2013. Disponível em: <http://enancib2013.ufsc.br/index.php/enancib2013/XIVenancib/paper/vi ew/284/319>. Acesso em: 30 mar. 2015.

SANTOS, P. L. A. da C.; SANT'ANA, R. C. G. Transferência da Informação: análise para valoração de unidades de conhecimento. DataGramaZero, v. 3, n. 2, abr., 2002. Disponível em: <http://www.dgz.org.br/abr02/Art 02.htm>. Acesso em: 6 mar. 2015.

SANTOS, P. L. V. A. C.; CORRÊA, R. M. R. Catalogação: trajetória para um código internacional. Niterói: Intertexto, 2009.

ZAFALON, Z. R. SCAN FOR MARC: Princípios sintáticos e semânticos de registros bibliográficos aplicados à conversão de dados analógicos para o formato MARC21 bibliográfico. 2012. 169f. Tese (Doutorado em Ciência da Informação) - Programa de Pós-Graduação em Ciência da Informação, Universidade Estadual Paulista, Marília, 2012. 